\title{
Direct Spectrophotometric Assay for Benzaldehyde Lyase Activity
}

\author{
Dessy Natalia, ${ }^{1}$ Christina Kohlmann, ${ }^{1}$ Marion B. Ansorge-Schumacher, ${ }^{2}$ and Lasse Greiner ${ }^{1,3}$ \\ ${ }^{1}$ ITMC, RWTH Aachen University, Worringerweg 1, 52056 Aachen, Germany \\ ${ }^{2}$ Insititute of Chemistry, Technical University of Berlin, Straße des 17. Juni 124, 10623 Berlin, Germany \\ ${ }^{3}$ DECHEMA e.V. Karl-Winnacker-Institut, Theodor-Heuss-Allee 25, 60486 Frankfurt am Main, Germany \\ Correspondence should be addressed to Lasse Greiner, greiner@dechema.de
}

Received 23 March 2011; Revised 25 May 2011; Accepted 8 June 2011

Academic Editor: Manuel Canovas

Copyright (C) 2011 Dessy Natalia et al. This is an open access article distributed under the Creative Commons Attribution License, which permits unrestricted use, distribution, and reproduction in any medium, provided the original work is properly cited.

Benzaldehyde lyase from Pseudomonas fluorescens Biovar I. (BAL, EC 4.1.2.38) is a versatile catalyst for the organic synthesis of chiral $\alpha$-hydroxy ketones. To allow fast assessment of enzyme activity, a direct spectrophotometric assay is desirable. Here, a new robust and easy-to-handle assay based on UV absorption is presented. The assay developed is based on the ligation of the $\alpha$-hydroxy ketone (R)-2,2' -furoin from 2-furaldehyde. A robust assay with direct monitoring of the product is facilitated with a convenient concentration working range minimising experimental associated with low concentrations.

\section{Introduction}

Benzaldehyde lyase (BAL; EC 4.1.2.38) from Pseudomonas fluorescens Biovar I (BAL, EC 4.1.2.38) belongs to the group of thiamine diphosphate- (ThDP-) dependent enzymes [1]. It is a versatile catalyst for the enantioselective synthesis of a broad variety of $\alpha$-hydroxy ketones by both $\mathrm{C}-\mathrm{C}$ bond coupling and kinetic resolution. These chiral compounds are important building blocks for the synthesis of several drugs and natural products [2-8].

According to its synthetic importance and application prospects, several methods for the determination of BAL activity have already been established. Most prominent are the uses of high pressure liquid chromatography (HPLC) or a combination of gas chromatography and mass spectroscopy (GC-MS) [3, 9]. However, these methods are material- and time-consuming when it comes to sample preparation and performance of measurements, and are therefore hardly applicable to the monitoring of fast reaction courses or large sample batches. For these purposes, establishment of spectrometric methods is highly desirable.

In fact, the BAL-catalysed carboligation of benzaldehyde into benzoin has been determined via spectrophotometry at a wavelength of $250 \mathrm{~nm}$. However, both benzaldehyde and benzoin revealed a considerable absorption at this wavelength resulting in an overlap for which a correction had to be carried out [1]. The same applies for the spectrophotometric determination of the condensation of furaldehyde into furoin at a wavelength of $277 \mathrm{~nm}$. Fluorescence spectroscopy at an excitation wavelength of $360 \mathrm{~nm}$ and an emission wavelength of $470 \mathrm{~nm}$ was used for the investigation of the carboligation of 3,5-dimethylbenzaldehyde (DMBA) into $3,3^{\prime}, 5,5^{\prime}$-tetramethoxybenzoin (TMB) [10]. However, the linear range of this assay strongly depends on the pathway of the excitation light [11]. Furthermore, the method is restricted to this substrate-product pair suffering from the same limited solubility as benzoin (see below). Generally, fluorescence spectroscopy is more difficult in handling and not as widely available.

BAL activity with regard to cleavage of $\alpha$-hydroxy ketones into aldehydes, can be determined with an indirect spectrophotometric assay. In a successive reaction, the product benzaldehyde is reduced by horse liver alcohol dehydrogenase (EC 1.1.1.1.) and the accompanying consumption of the cofactor NADH is measured at a wavelength of $340 \mathrm{~nm}$ [3]. However, even with addition of cosolvents such as DMSO or PEG the application of this method is strongly limited by the low solubility of the substrates such as benzoin [8]. In addition, the coupling of a second reaction adds to the error of activity determination.

To overcome the limitations imposed by the established assays we explored the direct monitoring of (R)-2,2'-furoin 


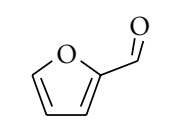

2-Furaldehyde
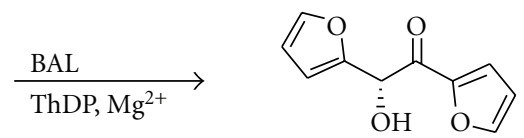

(R)-2,2' -Furoin
Figure 1: 2-furaldehyde (FA, CAS 98-01-1) condensation to 2,2' furoin (FO, (R)-2,2'-furoin, or (R)-1,2-di(furan-2-yl)-2-hydroxyketone, CAS 92921-36-3).

formation from 2-furaldehyde (Figure 1). This would allow to overcome the limitations of solubility, as maximum solubility of 2-furaldehyde in water $\left(0.86 \mathrm{~mol} \mathrm{~L}^{-1}\right)$ is orders of magnitude higher than benzoin or benzaldehyde (60 mmol L $\mathrm{m}^{-1}$; http://www.inchem.org/). Thus, addition of co-solvents, which is known to interfere with activity, is not required $[12,13]$.

\section{Materials and Methods}

2-furaldehyde (FA, CAS 98-01-1), furoin (FO, (R) 1,2di(furan-2-yl)-2-hydroxyketone, CAS 92921-36-3), and thiamine pyrophosphate (ThDP, CAS 154-87-0) were obtained from Sigma Aldrich. The furaldehyde was distilled and stored under argon atmosphere. Furoin was used without further purification. The solutions of furoin in water and buffer were obtained after filtration using polyamide filter with $0.45 \mu \mathrm{m}$ pore size.

Cells of E. coli SG13009/BAL $\mathrm{BL}_{\mathrm{His}}$ containing the overexpressed enzyme were kindly provided by Martina Pohl (Institute of Biotechnology 2, Research center Jülich, Germany). The cells were disrupted and BAL was purified via immobilized metal ion chromatography (Ni-NTA column) as described in the literatures [3,8]. Purified BAL was lyophilised and stored at $-20^{\circ} \mathrm{C}$ until use.

Potassium phosphate solution at a concentration of $50 \mathrm{mmol} \mathrm{L}^{-1}$ and $\mathrm{pH} 8$ containing $2.5 \mathrm{mmol} \mathrm{L}^{-1} \mathrm{MgSO}_{4}$ and $0.25 \mathrm{mmol} \mathrm{L}^{-1}$ ThDP was used as buffer. Under these conditions half life of BAL is known to be several hours $[10,13]$ excluding interference within the assay time span of minutes.

Initial rate measurement were carried out in 96-well microtiter plates. Typically, $5 \mathrm{mmol} \mathrm{L}^{-1}$ of substrate were reacted with $20 \mu \mathrm{L}$ BAL at $30^{\circ} \mathrm{C}$ for $2.3 \mathrm{~min}$ in which the absorbance was measured every $7 \mathrm{sec}$ (Power Wave HT, BioTek Instruments). The slope of linear regression was taken as activity. All measurements were carried out in triplicate, standard deviation (STD) is given as error. One unit activity is defined as the amount of enzyme that catalyses the formation of $1 \mu \mathrm{mol}$ of furoin per min. at $30^{\circ} \mathrm{C}$ and $\mathrm{pH} 8$.

\section{Results and Discussion}

Analysis of the components in the reaction mixture showed that all absorption maxima overlap considerably. The absorbance at $320 \mathrm{~nm}$ was chosen as the best compromise between sensitivity and interference. At $320 \mathrm{~nm}$ the extinction coefficient for 2-furaldehyde is more than one magnitude lower than for furoin (Figure 2). For comparison,

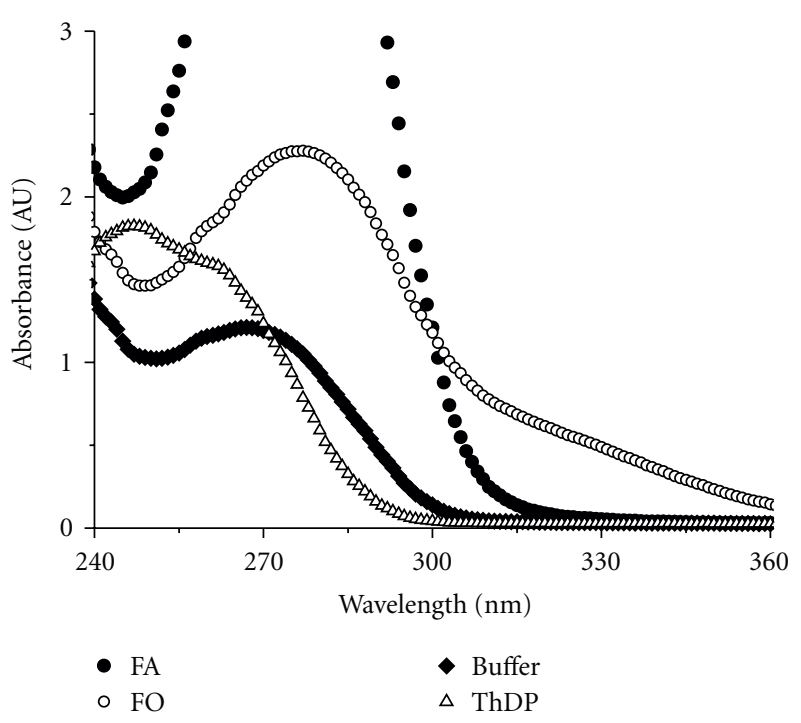

FIGURE 2: Spectra of substrate $\left(\bullet\right.$ FA, furaldehyde $\left.0.7 \mathrm{mmol} \mathrm{L}^{-1}\right)$, product $\left(\circ\right.$; FO, Furoin $\left.0.33 \mathrm{mmol} \mathrm{L}^{-1}\right)$, buffer with ThDP $(\diamond)$ $0.25 \mathrm{mmol} \mathrm{L}^{-1}$, and only ThDP $(\triangle) 0.25 \mathrm{mmol} \mathrm{L}^{-1}$ in water.

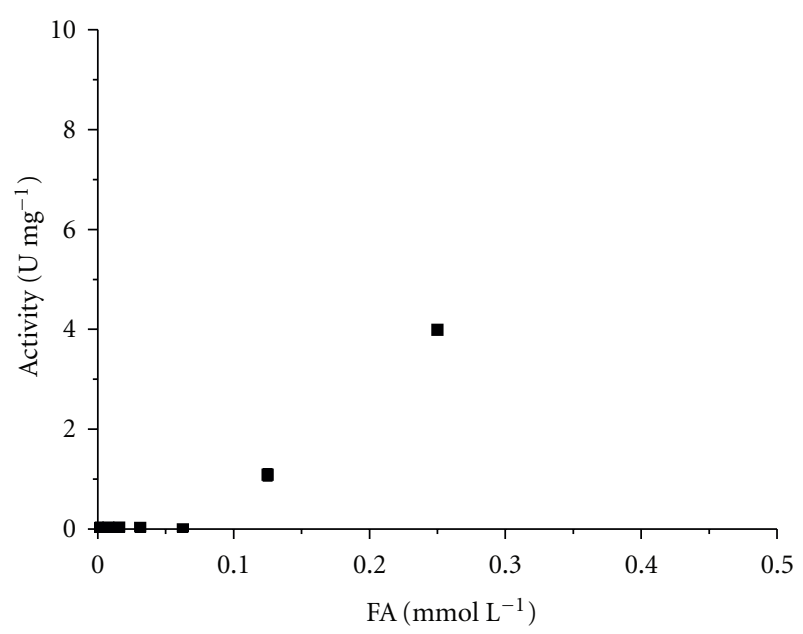

Figure 3: The absorbance of furaldehyde (FA) and furoin (FO) at $278 \mathrm{~nm}$ and (C) $320 \mathrm{~nm} \mathrm{~B}$ : activity of BAL as a function of concentration monitored in the accessible concentration range at $278 \mathrm{~nm}$.

the absorption at $278 \mathrm{~nm}$ as the peak maxima for both furoin and furaldehyde were determined. At $278 \mathrm{~nm}$ a low sensitivity is obtained as the absorbance is similar for both furaldehyde and furoin. Furthermore, a linear response is obtained only for concentrations below $0.3 \mathrm{mmol} \mathrm{L}^{-1}$. Whereas, a high sensitivity can be obtained at $320 \mathrm{~nm}$ in which furaldehyde absorption depends linearly on concentration up to $40 \mathrm{mmol} \mathrm{L}^{-1}$. The linear sensitivity for furoin is up to $1 \mathrm{mmol} \mathrm{L}^{-1}$ at $320 \mathrm{~nm}$ and $0.5 \mathrm{mmol} \mathrm{L}^{-1}$ at $278 \mathrm{~nm}$. The extinction coefficient for furaldehyde at $320 \mathrm{~nm}$ $\left(0.06 \mathrm{~L} \mathrm{mmol}^{-1} \mathrm{~cm}^{-1}\right)$ is much lower compared to furoin (1.67 $\mathrm{L} \mathrm{mmol}^{-1} \mathrm{~cm}^{-1}$ ), therefore the decrease of absorbance is at least 10 -fold lower than the increase. 


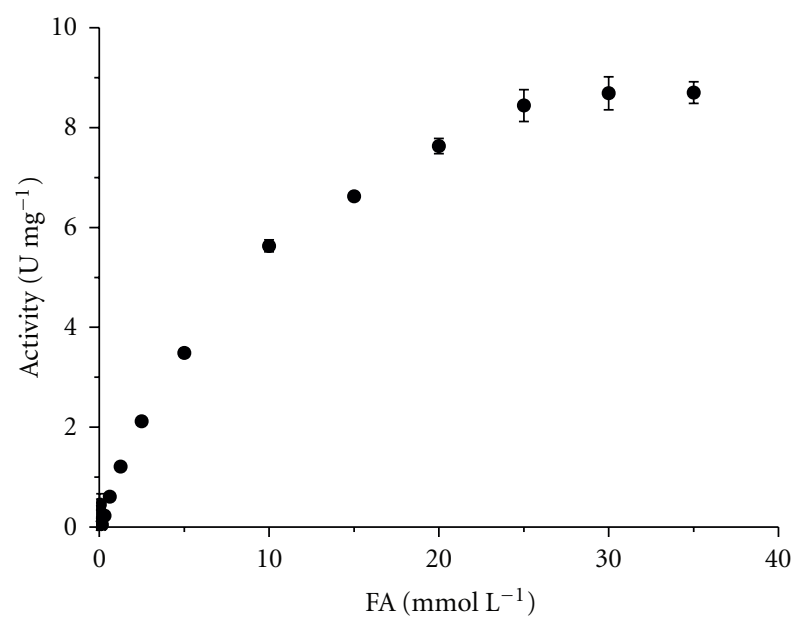

FIgURE 4: Activity of BAL as a function of concentration monitored in the accessible concentration range at $320 \mathrm{~nm}$.

The activity assay for measurement of absorbance at $320 \mathrm{~nm}$ increases the concentration range up to $40 \mathrm{mmol} \mathrm{L}^{-1}$ whereas the measurement of absorbance at 278 is not possible above $0.3 \mathrm{mmol} \mathrm{L}^{-1}$ due to detection limit of UV absorption (Figure 3 ). The activity as a function of substrate concentration for measurement at $320 \mathrm{~nm}$ can be described using a hyperbolic Michaelis-Menten-type equation with a $v_{\max }$ of $11.8 \pm 0.4 \mathrm{U} \mathrm{mg}^{-1}$ and $K_{\mathrm{M}}$ of $11.0 \pm 1.0 \mathrm{mmol} \mathrm{L}^{-1}$ (Figure 4).

\section{Concluding Remarks}

In summary, a robust and sensitive activity assay based on UV-spectrometry is proposed. It allows for relatively high concentrations of aldehyde thereby minimising experimental error. Furthermore, choosing a wavelength outside absorption maxima minimises interference with the other assay components.

\section{Abbreviations}

BAL: Benzaldehyde lyase

DMBA: 3,5-dimethylbenzaldehyde

DMSO: Dimethyl sulfoxide

FA: 2-furaldehyde

FO: $\quad$ (R) $-2,2^{\prime}$-furoin

(R)-1,2-di(furan-2-yl)-2-hydroxyketone

GS-MS: Gas chromatography-mass spectroscopy

HPLC: High-pressure liquid chromatography

$K_{\mathrm{M}}$ : Michaelis-Menten constant

$\mathrm{MgSO}_{4}$ : Magnesium sulfate

NADH: Nicotinamide adenine dinucleotide

Ni-NTA: Nickel-nitrilotriacetic acid

PEG: Polyethylene glycol

ThDP: Thiamine diphosphate

TMB: $3,3^{\prime}-5,5^{\prime}$-tetramethoxybenzoin

$\mathrm{U}$ : Unit activity

$v_{\text {max }}$ : Maximum activity.

\section{Conflict of Interests}

The authors have declared no conflict of interests.

\section{Acknowledgments}

The paper is funded by Deutsche Forschungsgemeinschaft via the DFG Graduate School 1166 BioNoCo-Biocatalysis in Non-Conventional Solvent (http://www.bionoco.org/). The authors thank Professor Martina Pohl (Institute of Biotechnology 2, Research Center Jülich, Germany) for providing the E.coli SG13009/BAL $\mathrm{Bis}_{\mathrm{H}}$ cells containing the recombinant BAL.

\section{References}

[1] B. González and R. Vicuńa, "Benzaldehyde lyase, a novel thiamine $\mathrm{PP}_{\mathrm{i}}$-requiring enzyme, from $P$ seudomonas fluorescens Biovar I," Journal of Bacteriology, vol. 171, no. 5, pp. 24012405, 1989.

[2] A. S. Demir, M. Pohl, E. Janzen, and M. Müller, "Enantioselective synthesis of hydroxy ketones through cleavage and formation of acyloin linkage: enzymatic kinetic resolution via C-C bond cleavage," Journal of the Chemical Society: Perkin Transactions 1, no. 8, pp. 633-635, 2001.

[3] E. Janzen, M. Müller, D. Kolter-Jung, M. M. Kneen, M. J. McLeish, and M. Pohl, "Characterization of benzaldehyde lyase from Pseudomonas fluorescens: a versatile enzyme for asymmetric $\mathrm{C}-\mathrm{C}$ bond formation," Bioorganic Chemistry, vol. 34, no. 6, pp. 345-361, 2006.

[4] M. B. Ansorge-Schumacher, L. Greiner, F. Schroeper, S. Mirtschin, and T. Hischer, "Operational concept for the improved synthesis of (R)-3,3'-furoin and related hydrophobic compounds with benzaldehyde lyase," Biotechnology Journal, vol. 1, no. 5, pp. 564-568, 2006.

[5] T. Hischer, D. Gocke, M. Fernandez et al., "Stereoselective synthesis of novel benzoins catalysed by benzaldehyde lyase in a gel-stabilised two-phase system," Tetrahedron, vol. 61, no. 31, pp. 7378-7383, 2005.

[6] A. S. Demir, O. Sesenoglu, P. Dünkelmann, and M. Müller, "Benzaldehyde lyase-catalyzed enantioselective carboligation of aromatic aldehydes with mono- and dimethoxy acetaldehyde," Organic Letters, vol. 5, no. 12, pp. 2047-2050, 2003.

[7] R. J. Mikolajek, A. C. Spiess, M. Pohl, S. Lamare, and J. Büchs, "An activity, stability and selectivity comparison of propioin synthesis by thiamine diphosphate-dependent enzymes in a solid/gas bioreactor," ChemBioChem, vol. 8, no. 9, pp. 10631070, 2007.

[8] M. Pohl, M. Müller, and A. Demir, "Nucleotide sequence encoding a benzaldehyde lyase, and process for stereoselectively synthesizing 2-hydroxyketones," US Patent 7,045,334 B2, May 16,2006.

[9] P. Ayhan, I. Simsek, B. Cifci, and A. S. Demir, "Benzaldehyde lyase catalyzed enantioselective self and cross condensation reactions of acetaldehyde derivatives," Organic and Biomolecular Chemistry, vol. 9, no. 8, pp. 2602-2605, 2011.

[10] A. van den Wittenboer, Stabilitäten der Benzaldehydlyase aus Pseudomonas fluorescens und der Carbonylreduktase aus Candida parapsilosis in wässrig-organischen Zweiphasensystemen, Ph.D. dissertation, RWTH Aachen University, 2010.

[11] M. Pohl, "Personal communication," 2010. 
[12] T. Schmidt, M. Zavrel, A. Spie $\beta$, and M. B. AnsorgeSchumacher, "Biochemical peculiarities of benzaldehyde lyase from Pseudomonas fluorescencens Biovar I in the dependency on $\mathrm{pH}$ and cosolvent concentration," Bioorganic Chemistry, vol. 37, no. 3, pp. 84-84, 2009.

[13] S. Shanmuganathan, D. Natalia, A. van den Wittenboer, C. Kohlmann, L. Greiner, and P. Domínguez De María, "Enzyme-catalyzed C-C bond formation using 2-methyltetrahydrofuran (2-MTHF) as (co)solvent: efficient and biobased alternative to DMSO and MTBE," Green Chemistry, vol. 12, no. 12, pp. 2240-2245, 2010. 

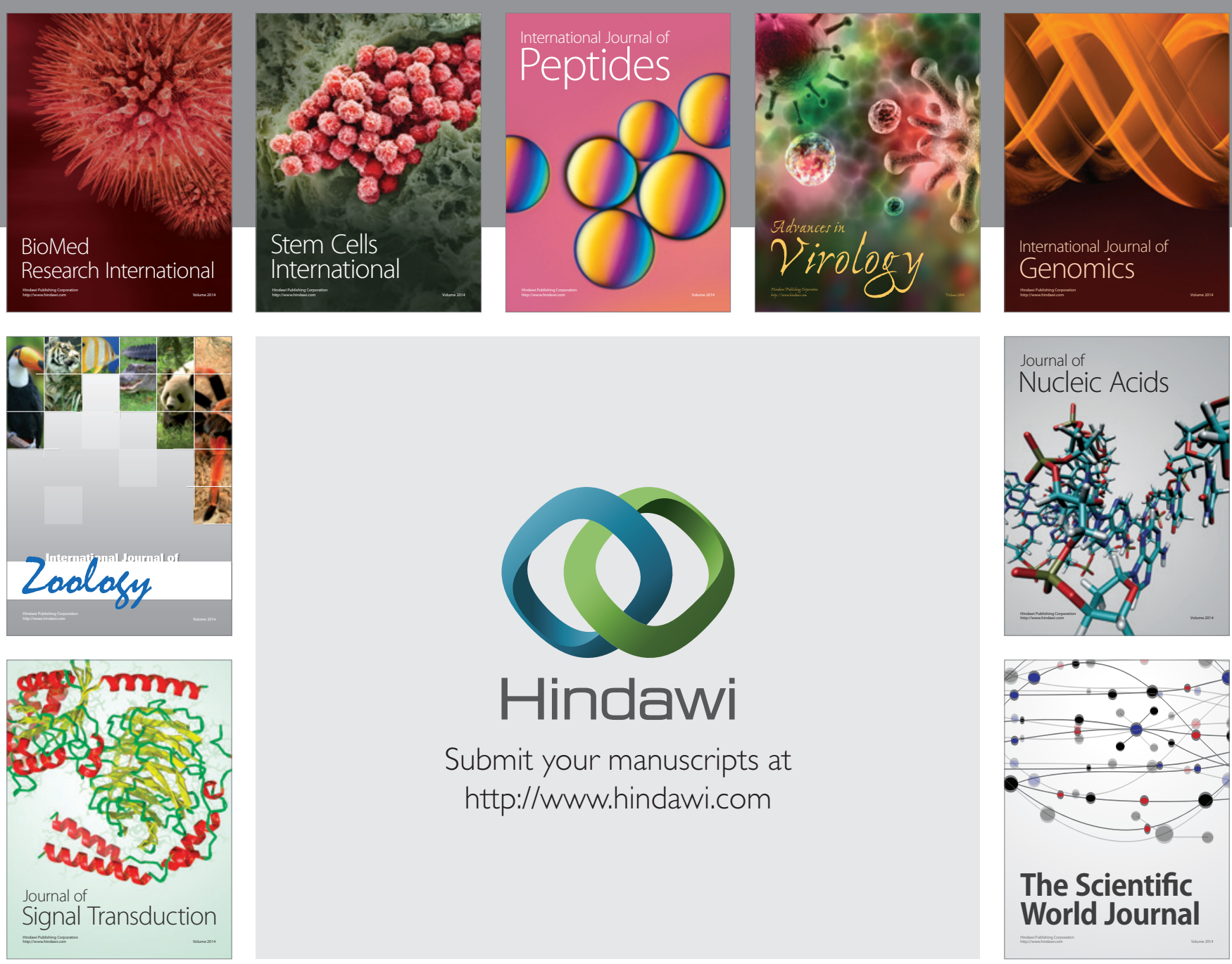

Submit your manuscripts at

http://www.hindawi.com
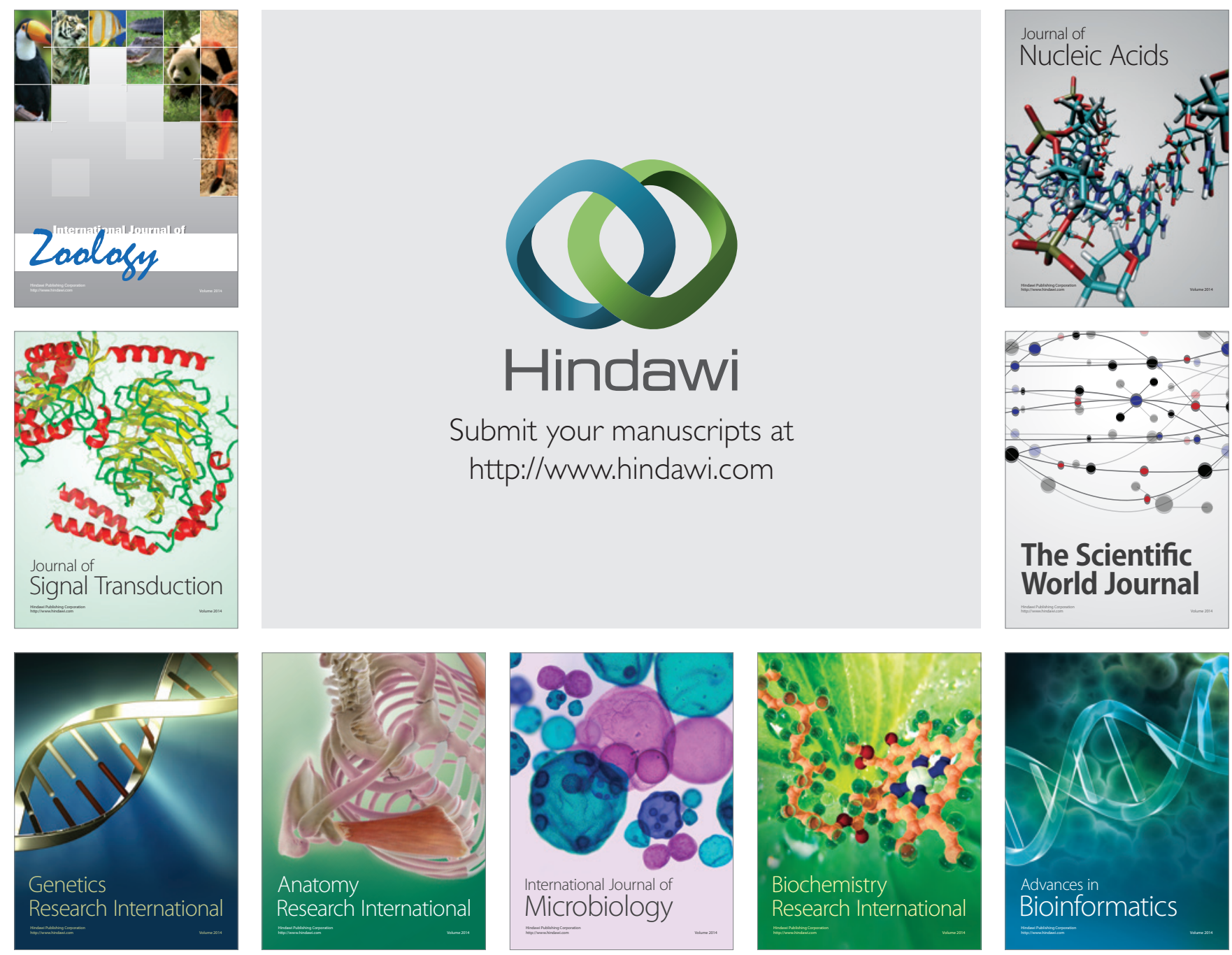

The Scientific World Journal
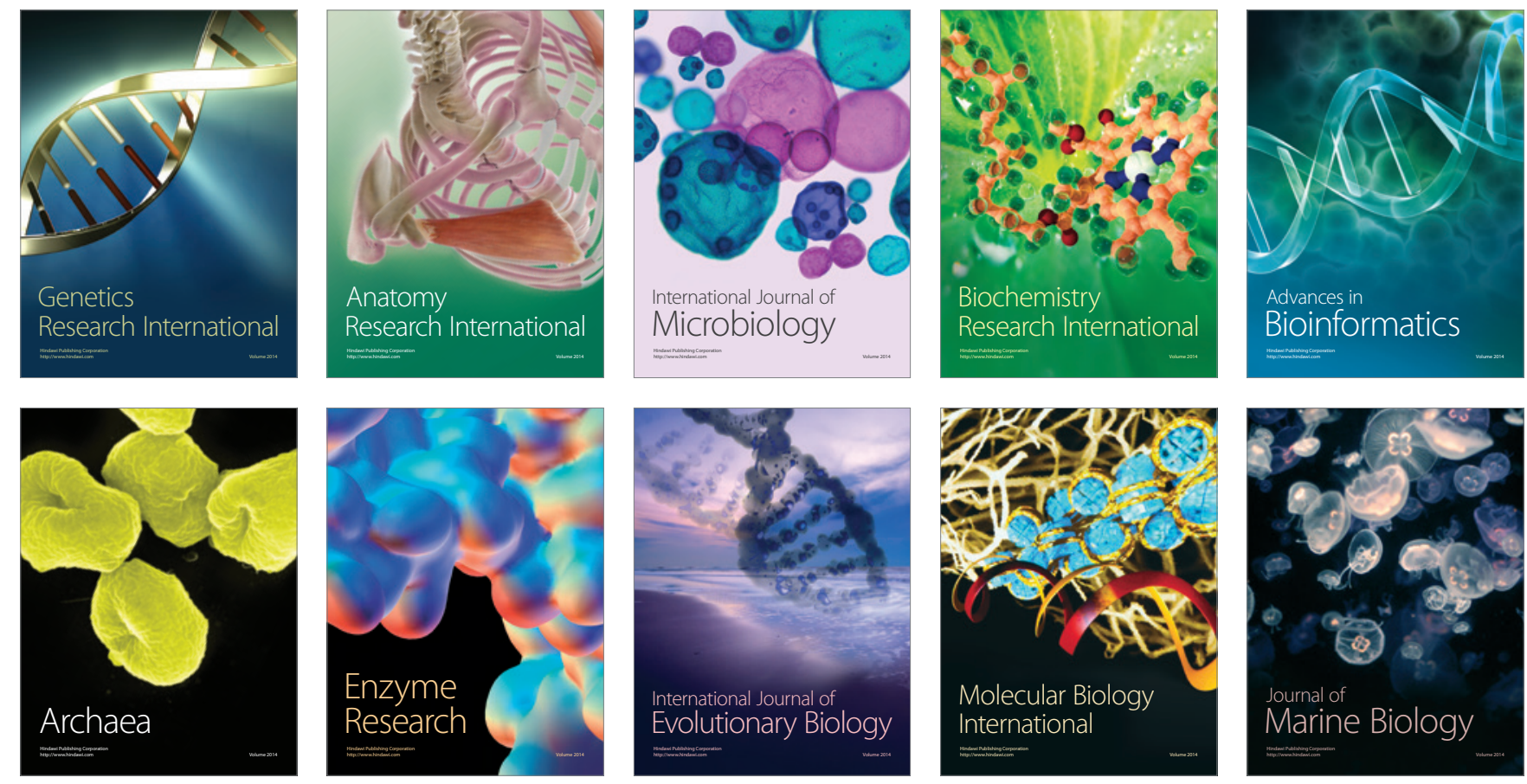